\title{
A Single Espresso, Please! Rationalizing Espresso Price Dispersion Across Italian Cities
}

\author{
Flavio Delbono ${ }^{1} \cdot$ Gemma Dipoppa $^{2}$. \\ Luca Lambertini ${ }^{1}$. Carlo Reggiani ${ }^{3}$
}

Received: 26 July 2016 / Revised: 18 December 2016 /

Accepted: 25 January 2017/ Published online: 10 February 2017

(C) The Author(s) 2017. This article is published with open access at Springerlink.com

\begin{abstract}
This paper aims at providing an explanation of the observed espresso price dispersion across major Italian cities. We present some preliminary empirical evidence that suggests a positive relationships between the average espresso price in a city and the number of coffee shops (normalized for the adult population) operating in that city. The finding is shown to be robust after controlling for GDP per capita and consumers' price index. We provide an interpretation of the empirical findings relying on a model of price competition where firms adjust the mark-up to offset the negative effect of any increase in their number.
\end{abstract}

Keywords Price dispersion · Espresso prices · Market competition

JEL Classification L11 $\cdot$ L13 $\cdot$ L66

\section{Introduction}

For the average Italian adult, drinking an espresso is not only a ritual, but it is most often a repeated ritual during the day. According to anecdotal evidence, espresso is the second most drunken beverage in Italy (water being first), dozens million cups being consumed daily.

\section{Carlo Reggiani}

carlo.reggiani@manchester.ac.uk

Gemma Dipoppa

gemmad@sas.upenn.edu

Flavio Delbono

flavio.delbono@unibo.it

Luca Lambertini

luca.lambertini@unibo.it

1 Department of Economics, University of Bologna, Bologna, Italy

2 Department of Comparative Politics, University of Pennsylvania, Philadelphia, PA, USA

3 School of Social Sciences-Economics, University of Manchester, Manchester, UK 


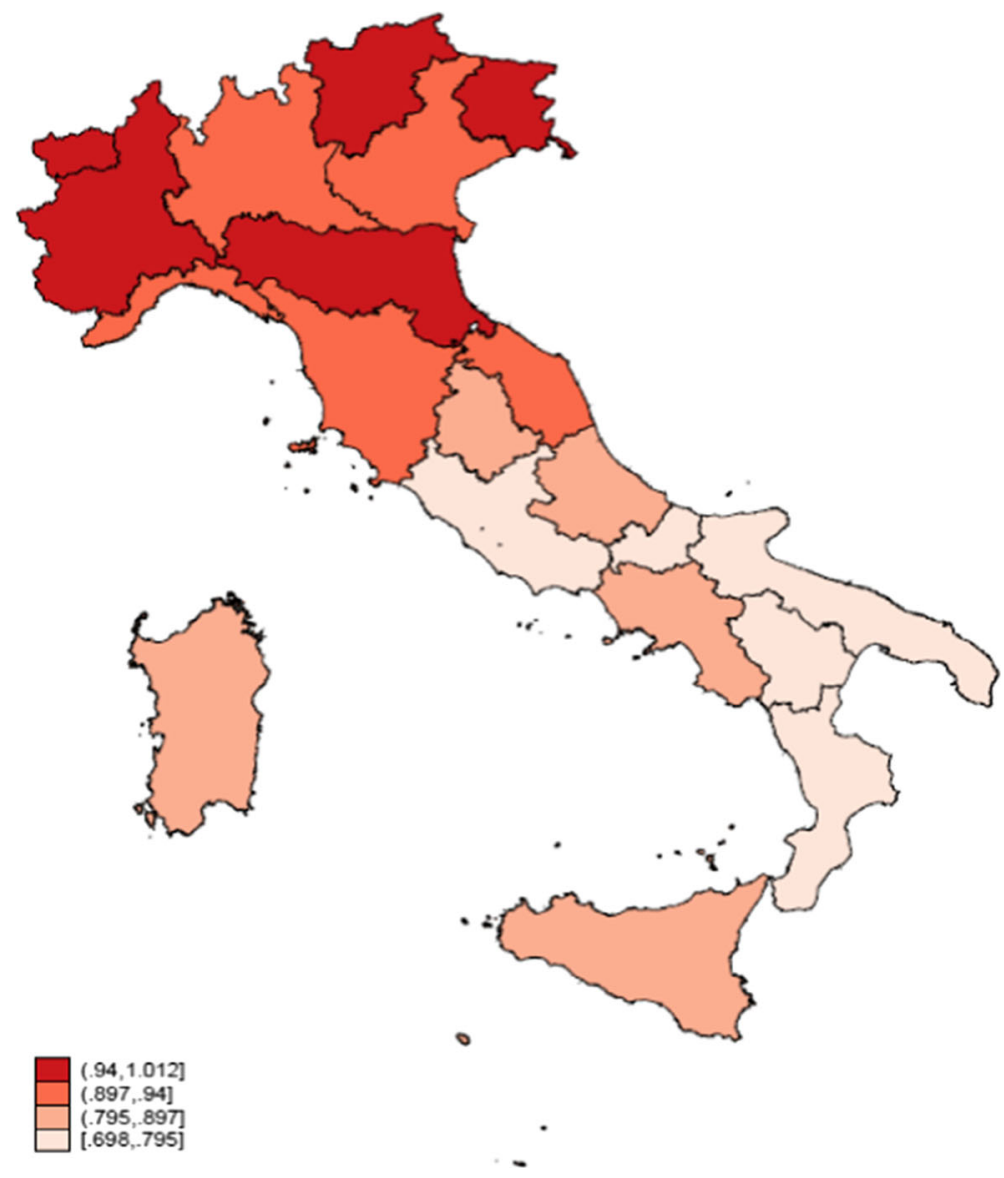

Fig. 1 Coffee prices in Italian regions, 2011

A discerning consumer travelling from Northern to Southern Italian cities would probably notice a non-negligible fall in espresso prices. Actually, in major Italian cities espresso cups are priced in bars very similarly within cities ${ }^{1}$ and very differently across cities. ${ }^{2}$ For instance, in 2001 the average price ${ }^{3}$ charged in Milano was 0.78 euros; the price declines to 0.62 in Roma and even more in Palermo, 0.56. In 2011, the last year in our sample, the dispersion across cities did not change much as it ranged from 1.01 euros in Bologna to 0.79 in Roma and 0.71 in Bari. Figure 1 visualises the geographic price dispersion of espresso in Italy in 2011 (prices are in Euros).

\footnotetext{
${ }^{1}$ For example, in 2014 the price range of an espresso cup in euros was in Venice 0.90-1.00, in Bologna 1.00-1.10 and in Rome 0.80-0.90 (Source: http://osservaprezzi.sviluppoeconomico.gov.it/index.php?).

${ }^{2}$ In what follows we refer to "bar" to indicate a plethora of establishments selling coffee (coffee shops, cafeterias, pubs...), excluding restaurants. More details are provided in Appendix A.1 describing the dataset. ${ }^{3}$ By average price we mean the price charged for a cup of single espresso drunk standing at the counter. Unlike many other countries, this is the standard way Italians consume espresso. Hence, the sample excludes the service surcharge applied by cafeterias to the price of espresso when customers sit down.
} 
Since the standard espresso drunk at the bar is a fairly homogeneous good, except for location, broad price differences between cities look surprising. Moreover, our data suggest a large variance in the potential number of consumers per bar across cities. In particular, it turns out that higher prices are associated to a lower number of adult inhabitants per bar (a proxy for the potential clients of a bar).

More in details, our simple empirical analysis focuses on the distribution of espresso prices in the 20 Italian regional capitals, a sample including the most populated Italian cities, between 2001 and 2011. The basic descriptive statistics of the sample: (i) confirm the coffee price dispersion between cities, and (ii) reveal a negative correlation between espresso prices and the potential number of customers per bar. For instance, in 2011, the upper limit of one euro is the price approached when the number of inhabitants per bar falls below 400 .

Using data relating to four years within the period, we estimate a Linear Regression Model with Fixed Effects and show that increasing the potential number of customers per bar (or decreasing the number of bars with respect to the population) has a negative and significant impact on the espresso price. The result is obtained controlling for both GDP per capita and city consumers' price indices.

These facts give rise to interesting questions: why prices are so high in some cities and not in others? Does the number of potential consumers per bar play a role in explaining these large differences in prices?

Price dispersion and the high price of espresso in presence of more inhabitants per bar are stylised facts compatible with several different explanations. A huge (micro and macro) literature has focused on deviations from the "Law of One Price" and, hence, explanations of price dispersion and the so-called "Penn Effect", establishing a positive relation between price levels and income. ${ }^{4}$ Industrial Organization theory suggests that high prices in presence of a high number of firms may be a symptom of collusion between firms. On those grounds, we then critically consider the relevant streams of literature, by relating them to the evidence provided and the main characteristics of the espresso sector in Italy. This exercise allows highlighting inconsistencies with most alternative explanations, including: (i) theoretical approaches to price dispersion based on imperfect information, and (ii) theories of implicit or explicit collusion.

Ultimately, the approach that seems most consistent with our evidence and the features of the Italian coffee sector is based on variable markups and upon the Dastidar (1995) model of one-shot price competition with homogeneous goods and convex costs. According to the Dastidar model a price equilibrium outcome mimicking joint profit maximization may indeed emerge as a non-cooperative equilibrium even without repetition. We show that our empirical findings fit better Dastidar's conclusion than the traditional approaches (imperfect information and collusion) mentioned above. In particular, consistently with the comparative statics properties of Dastidar's model, the empirical evidence, although rather preliminary, suggests a positive relationship between the average espresso price in a city and the number of bars, or conversely, higher prices tend to prevail in cities with a lower number of inhabitants per bar (potential clients). Our empirical findings are then rationalised within this model, by showing that each price setting company in a homogeneous industry compensates the competitive effect of an increase in the number of firms by increasing the markup with respect to the average cost.

The rest of the paper is organized as follows. In Section 2, we present the statistical evidence. Section 3 critically discusses the related literature in the light of our empirical results

\footnotetext{
${ }^{4}$ Crucini and Yilmazkuday (2014) provide an in-depth review of the extensive literature.
} 
Table 1 Descriptive statistics

\begin{tabular}{llllll}
\hline & Obs & Mean & Std Dev & Min & Max \\
\hline Espresso Price & 78 & 0.78075 & 0.11517 & 0.56 & 1.012 \\
Inhabitants per bar & 80 & 537.777 & 188.702 & 294.529 & 1239.579 \\
GDP per capita & 80 & 25400 & 7035.102 & 13800 & 46600 \\
Price Index & 77 & 113.6266 & 9.4284 & 101.8 & 130.9 \\
\hline
\end{tabular}

on the Italian espresso sector. Section 4 discusses price competition under convex costs and bridges the theoretical model and the empirical evidence. Section 5 briefly concludes. The Appendix contains a detailed description of the data set (A.1) and some robustness checks (A.2).

\section{Empirical Analysis}

\subsection{Data}

We perform an empirical analysis on the distribution of espresso prices in Italy. The lack of data available (particularly espresso prices at the city level) constitutes an important constraint to our analysis. In Appendix A.1 we provide a detailed account of how we constructed the sample. Generally, our analysis focuses on the capital cities of the 20 Italian regions in the years 2001, 2005, 2009 and 2011, for a total of about 80 observations. The espresso prices are collected by Italian National Institute of Statistics (henceforth ISTAT). For each city, we also have information about the number of bars, the total adult population, ${ }^{5}$ the consumers price index (ISTAT) and the GDP per capita (Eurostat). From the previous sources, we compute the inhabitants per bar, a proxy of the potential clients per bar in each city: this variable can be interpreted as the potential quantity. The descriptives of the sample are summarized in Table 1.

In the period of our study, the average price of a cup of coffee in an Italian bar was slightly less than 80 euro cents. A standard deviation of 11.5 cents, however, reveals a $15 \%$ coefficient of price variation. A bar has an average potential of 540 customers. Also the potential clientele varies greatly across the country, with a proportion of more than one to four between the extreme cities. The mean GDP per capita per city in our sample was 25400 euros. The per capita GDP displays a very sharp geographical variation between Italian regions (in particular, North vs South), but the variation in our sample is also due to the fact that our study covers a period of 10 years. Interestingly, although spatial and intertemporal variations are present, the consumers' Price Index is the less volatile among the variables used in our study.

\subsection{Some Preliminary Evidence}

Observing the raw data we detect the presence of a negative relationship between the price of espresso and the number of inhabitants per bar, our proxy for the potential clientele. The scatter plot displays a downward pattern that approaches the average price of 1 euro

\footnotetext{
${ }^{5}$ The total adult population is officially defined by ISTAT as residents of 15 years of age or above.
} 


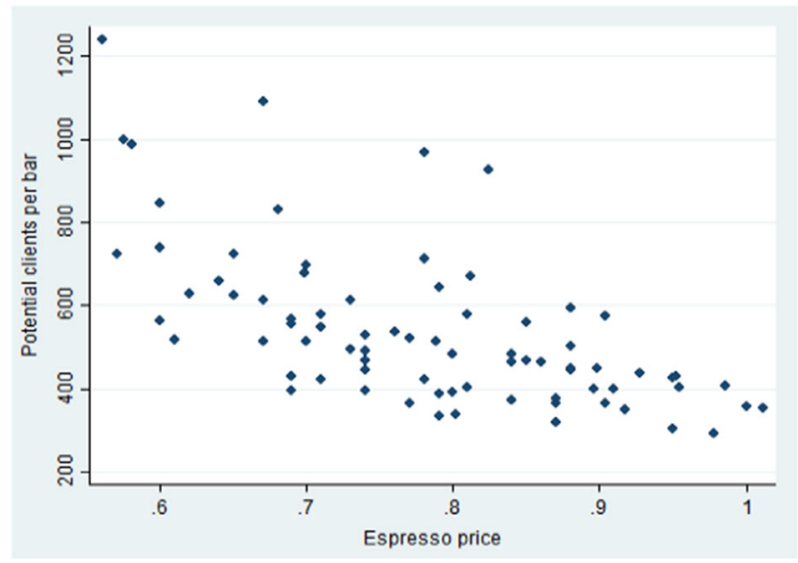

Fig. 2 Inhabitants per bar and espresso prices, all years

when inhabitants per bar are less than 400 . The relationship is confirmed by the correlation coefficient of -0.6292 (Fig. 2).

The previous descriptive evidence is not sufficient to explain the observed pattern of espresso prices in Italy. For a better understanding of the price dispersion, we need at least to control for a number of other factors. In particular, price dispersion is likely to be explained by variables like cities' GDP per capita and general consumers' price indices. Common sense and the previous literature suggest that richer cities should experience higher price levels (the well-known "Penn effect"), including higher espresso prices.

Given the panel structure of our dataset, we estimate a Linear Regression Model and compare a standard OLS estimation with a model including Fixed Effects (FE). More precisely, we use the following specification:

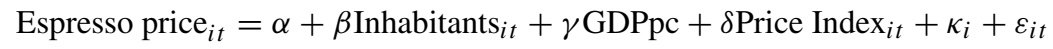

where $t$ indicates the year, $i$ the city and $\kappa_{i}$ represents the city fixed effect; clearly, in the OLS estimation $\kappa_{i}=0$. This specification is rooted in the empirical literature on price dispersion, the "Law of One Price" and the so called "Penn Effect". ${ }^{6}$ For ease of interpretation of the following results, the variable Inhabitants is measured in hundreds of inhabitants per bar and GDPpc in thousands of euros.

Table 2 presents our main results.

First, we can note that the model specification (OLS vs FE regression) does not majorly affect the significance of the coefficients. A further comparison of columns (1) and (2) shows how the OLS regression tends to underestimate the contribution of each independent variable to the price dispersion of coffee between Italian cities. The following discussion is then based on the FE results in column (2).

\footnotetext{
${ }^{6}$ As already recalled, this literature is exhaustively reviewed in Crucini and Yilmazkuday (2014); in Section 3 we will discuss some contributions more specifically in relation to our evidence.
} 
Table 2 Espresso price in Italian cities

Notes:
$* \mathrm{p}<0.1, * * \mathrm{p}<0.05, * * * \mathrm{p}<0.01$.
Dependent variable: Espresso
Price. Column (1) is estimated
with
ordinary least squares regression.
Column ( 2 ) and ( 3 ) are estimated
with city-level fixed effects.
Robust standard
errors below the coefficient in
brackets.

\begin{tabular}{llll}
\hline & $(1)$ & $(2)$ & $(3)$ \\
& OLS & $\mathrm{FE}$ & $\mathrm{FE}$ \\
\hline Inhabitants & $-0.01544 * *$ & $-0.06275^{* * *}$ & $-0.04616^{* *}$ \\
& $(0.006897)$ & $(0.01333)$ & $(0.016636)$ \\
GDPpc & $0.008121 * * *$ & $0.020878 * * *$ & $0.021599 * * *$ \\
& $(0.001809)$ & $(0.006672)$ & $(0.006569)$ \\
Price Index & 0.0012311 & -0.0003536 & \\
Constant & $(0.0010023)$ & $(0.0003424)$ & \\
& $0.518524 * * *$ & $0.618089 * *$ & $0.478162 *$ \\
Overall $R^{2}$ & $(0.136952)$ & $(0.239975)$ & $(0.243301)$ \\
Obs & 0.5084 & 0.4916 & 0.5307 \\
\hline
\end{tabular}

Second, we focus on the regressors. Fairly surprisingly, the city level consumers' Price Index is not statistically significant in explaining espresso prices. ${ }^{7}$ To interpret this finding it is worth noting that the consumers' price index maybe considered as a proxy for the production cost level. The labour costs account for about $60 \%$ of the total cost of espresso. This cost does not vary across Italian cities because it is set by collective bargaining at national level. This fact may explain the lack of association between the price of espresso and the price index at city level.

The GDP per capita, instead, has a statistically significant role in explaining the espresso price dispersion. A thousand euros increase in the GDP per capita has an estimated positive impact of 2 cents on the price of a cup. The finding is not only intuitive but it is broadly in line with the received literature: Frankel and Gould (2001), for example, show that prices are lower in cities with a significant presence of lower middle-income households.

Last but not least, evidence shows that increasing the inhabitants per bar, a proxy for the potential number of clients, has a significant and negative effect. In particular, an extra hundred inhabitants per bar is estimated to lead to an average decrease of 6.2 cents in the price of espresso. Whereas the variable is likely to be endogenous as supply and demand factors concur to define the number of inhabitants per bar, the latter finding is rather counterintuitive. There are two ways of thinking about it: either increasing demand per bar yields a fall in espresso prices or increasing the number of sellers for a given population of potential consumers increases espresso prices. This finding calls for a theoretical rationalization, thoroughly discussed in the next sections.

Finally, in column (3) we stick to a FE regression model but the Price Index, highly insignificant in the previous specifications, is omitted. The results are in line with the previous specifications with respect to the signs and significance of the coefficients. ${ }^{8}$

\footnotetext{
${ }^{7}$ We included both GDP per capita and consumers' price levels among the regressors as they are not highly collinear. This evidence seems to rule out the Penn effect, according to which the price level is higher in richer cities. See Crucini and Yilmazkuday (2014) for a careful discussion of the Penn effect across (traded) goods and cities.
}

${ }^{8}$ Appendix A.2 provides further robustness checks of our conclusions. 


\section{Rationalizing the Evidence: a Plethora of Explanations}

The previous analysis established: (i) price dispersion in the price of coffee between Italian cities, and (ii) the negative relationship between the price and the number of bars per inhabitants. Although possibly counterintuitive, these findings might be rationalized in a number of ways. In particular, two classical issues in economics are: (i) the Law of One Price and deviations from it, and (ii) the relationship between the intensity of competition (as measured by the number of firms) in one market and its equilibrium price. Both issues are closely related to the evidence we provided about the price of a coffee and have been tackled in a vast literature, both at the theoretical and at the empirical level. In what follows, we briefly discuss these literatures and discuss how they relate to our findings and to the features of the Italian coffee sector. We finally argue that the evidence provided is mostly consistent with an explanation based on variable markups and price competition in presence of diseconomies of scale.

\subsection{The Law of One Price, Price Dispersion and Competition}

The empirical evidence comes from international comparisons as well as from city and/or sector specific analyses. Crucini and Yilmazkuday (2014) distinguish between micro (industry/city level) deviations from the law of one price and aggregate deviations related to the "Penn effect". They also provide a more in-depth review of the extensive literature. However, a distinguishing characteristic of the literature dealing with either topic is its focus on traded goods.

A fairly small portion of the applied research focuses on non-traded goods or services. Some of these contributions - for instance Pauly and Sattherthwaite (1981) and Goolsbee and Goolsbee and Syverson (2008) - find a positive relationship between the number of competitors in an industry and the market price. ${ }^{9}$ Our paper provides further evidence in favour of this last finding by showing that the price of a non-traded good like an espresso cup is higher in those cities with higher number of bars.

Two main differences distinguish our work from these contributions. First, while Pauly and Sattherthwaite (1981) and Goolsbee and Syverson (2008) consider local markets for services, we focus on a physical good. Moreover, the pricing of an espresso is typically routine: unlike physician services, experience or signalling considerations hardly matter and neither capacity constraints nor intertemporal sorting play a role, as in airline pricing. Second, contrary to some received literature, ${ }^{10}$ the wage differentials across markets (cities) cannot play a significant role in our analysis because the Italian labour market accommodates a nation-based wage rate for bar employees. Hence, price differentials of the main input can hardly explain espresso price differentials across cities.

On the theoretical side, most research trying to rationalize price dispersion relies upon search costs generated by asymmetric information. Price differentials emerge in equilibrium because of costs incurred by potential buyers in gathering information about the prices

\footnotetext{
${ }^{9}$ For further evidence in support of such a relationship, see Chen and Riordan (2008).

${ }^{10}$ Yilmazkuday (2014), for instance, shows that marginal cost differentials explain about $70 \%$ of price dispersion across US districts of entry.
} 
charged by retailers. In our case, search costs are basically immaterial. However, search costs need not to be at work to observe price differentials even in homogeneous and Internet accessible goods, as recent evidence suggests. ${ }^{11}$ A number of other factors may be the driver of price dispersion as consumers' loyalty and ex-ante heterogeneity in consumers and firms (Baye et al. 2006). None of these, however, is likely to explain the heterogeneity of the price of coffee in Italian cities.

Last but not least, another approach to explain price dispersion of a non-traded homogeneous good relies upon differences in consumers' income. Whereas we cannot provide conclusive evidence, the case of an important city like Bologna suggests that this is unlikley to be happening in the Italian coffee sector. Intuition, in fact, may suggest that richer city areas entail higher espresso prices. However, this can be misleading: within the same city, Bologna, espresso prices are basically flat across districts, ${ }^{12}$ despite very large differences in income per capita across city districts. In 2005 district level citizen's incomes ranged betweeen about 17,000 to over 40,000 Euro, whereas in 2012 the equivalent range was between less than 19,000 to over 42,000 Euro (Bologna City Council; 2009, 2014). Moreover, higher income areas may have more bars per capita, as for example consumers' in richer areas may be willing to pay more to avoid queues: this interpretation is not fully in line with the evidence from Bologna's districts, in which the correlation between income and the number of bars is positive but only 22.64 percent.

\subsection{Cartels and Tacit Collusion}

The theory of Industrial Organization suggests other potential explanations for our evidence, mostly based upon collusion. ${ }^{13}$ The first and well known relies upon explicit collusion: firms in each city may communicate and set up an agreement to sustain a high price-cost margin. Italian bars are usually members of professional associations. It is not rare for these associations to suggest "focal" price levels for espresso. This could be a factor facilitating collusion or, at least, coordination of price levels across bars. A second interpretation may be based on tacit collusion in a repeated game: firms repeatedly interact in the market, making it potentially possible to sustain a high prices, under the threat of punishment in case of deviations. ${ }^{14}$

There are, however, at least two characteristics of the Italian espresso market that are hardly compatible with the two above classical explanations. First, the number of bars/firms is large in all cities because the Italian espresso market is extremely fragmented for the lack of chains like Starbucks. ${ }^{15}$ Second, in many cities demand is seasonally fluctuating because of tourists' flows and the discontinuous presence of students. Both factors are known in the literature as obstacles to implement and sustain collusive agreements.

\footnotetext{
${ }^{11}$ See, inter alia, Gorodnichenko and Talavera (2017) and Gorodnichenko et al. (2015).

${ }^{12}$ This is a peculiarity of espresso prices in Italy and it is in contrast, for example, to the evidence provided by Eizenberg et al. (2016).

${ }^{13}$ Marshall and Marx (2012) provide an excellent overview of the economics of cartels and collusion, including the different implications of explicit and implicit agreements.

${ }^{14}$ The collection of results on the stability of this type of tacit collusion, based on the so called "supergames", are known as "folk theorems": Vives (1999), Ch. 9, provides an overview of the main results of this literature.

${ }^{15}$ To this regard, see for instance http://www.bbc.com/news/business-33527053.
} 


\subsection{Variable Markups and Price Competition}

As noted in the Introduction one may frame our statistical results by relying upon an interpretation based on variable markups. The literature on constant versus variable markups and its relationship with the analysis of departures from the Law of One Price is extensive: Yilmazkuday (2016) is a recent example and contains an up to date review of the literature with the most relevant references. That stream of literature focuses mostly on traded goods and international price differentials; in our case, instead, variable markups may operate within regions in the same country and, more importantly, for a non-traded good. The mechanism, as we explain in details in Section 4, is provided by the Dastidar (1995) model of price competition under convex costs: in there, firms may react to the pro-competitive effect of an increase in their number by compensating it with an anti-competitive effect driven by an upward adjustment in the markup.

\section{Price Competition and Convex Costs}

The model of price competition under convex costs of Dastidar (1995) is the best frame that we use to rationalize our empirical findings and we now present it in details.

Dastidar's model is important for the analysis of market competition under price-setting behavior because it allows proving the existence of a continuum of pure-strategy Nash equilibria in the price space under regular demand and convex variable costs. We shall focus on a linear-quadratic version of his original model.

The market is supplied by a population of $n \geq 1$ identical firms. The product is homogeneous and its demand function is $p=a-Q$, where $Q=\Sigma_{i=1}^{n} q_{i}$ is aggregate output $p$ is price and $a$ is a positive parameter proxying the size of the market. All firms produce with the same technology, to which a cost function $C_{i}=b q_{i}+c q_{i}^{2} / 2$ is associated, where $c$ is a positive parameter, and $b \in[0, a)$. The profit function of firm $i$ is then

$$
\pi_{i}=\left(p-b-\frac{c q_{i}}{2}\right) q_{i}=\left(a-q_{i}-Q_{-i}-b-\frac{c q_{i}}{2}\right) q_{i}
$$

where $Q_{-i}=\Sigma_{j \neq i} q_{j}$.

The non-cooperative one-shot game takes place under complete, symmetric and imperfect information. The solution concept is the Nash equilibrium, which here involves all firms setting the same price $p^{*} \in\left[p^{a v c}, p^{u}\right]$. At the lower bound $p^{a v c}$, equilibrium price equals average variable costs, so that firms are indifferent between producing or not. At the upper bound $p^{u}$, the equilibrium price is such that firms would be indifferent between playing $p^{u}$ or marginally undercutting it in order to capture the entire market demand.

The continuum of price equilibria is ${ }^{16}$

$$
p^{B N}=\frac{a c+2 b(n-\alpha)}{c+2(n-\alpha)}
$$

where $B N$ stands for Bertrand-Nash, and $\alpha$ is a parameter whose range is $\alpha \in$ $\left[0, n^{2} /(1+n)\right]$. In particular:

\footnotetext{
${ }^{16}$ See Dastidar (1995, pp. 27-28), Gori et al. (2014, pp. 373-75) and Delbono and Lambertini (2016).
} 
- if $\alpha=0$, the equilibrium price equals average variable cost;

- at $\alpha=n / 2$, marginal cost pricing obtains;

- if $\alpha=n^{2} /(1+n), p^{B N}$ reaches the highest level above which undercutting takes place.

Taking the partial derivatives of Eq. 3 with respect to $n$ (treated as a continuous variable) and $\alpha$, we get

$$
\begin{gathered}
\frac{\partial p^{B N}}{\partial n}=-\frac{2(a-b) c}{[c+2(n-\alpha)]^{2}}<0 \\
\frac{\partial p^{B N}}{\partial \alpha}=-\frac{\partial p^{B N}}{\partial n}=\frac{2(a-b) c}{[c+2(n-\alpha)]^{2}}>0
\end{gathered}
$$

The partial derivative in Eq. 4 tells that, in the Bertrand-Nash equilibrium, an increase in the number of firms unambiguously decreases market price. The partial derivative in Eq. 5 reveals that the equilibrium price increases with $\alpha$ at the same rate with which price decreases with respect to the number of firms. Therefore, the isoprice curve in the space $(n, \alpha)$ is a straight line increasing at $45^{\circ}$. This amounts to saying that the price-setting firms compensate the negative effect of an increase in their number by increasing $\alpha$. If the latter increases more than proportionately with respect to $n$, the equilibrium price increases.

This result is also in line with Dastidar (2001) showing that if the second derivative of the cost function is non-increasing in output, it is easier to sustain collusion when the number of firms increases. Indeed, our cost function meets such condition.

\subsection{Bridging Evidence and Theory}

Our context suits (Dastidar 1995) assumption of cost convexity. Indeed, according to a recent professional association report (FIPE, 2013), in the average Italian bar, labour costs account for about $60 \%$ of the total espresso cost, whereas raw coffee weights $22 \%$ and rents and other costs account for $18 \%$. Hence, the incidence of labor costs makes the hypothesis of convex variable costs plausible. Moreover, different rents likely account for the mild dispersion of espresso prices within each city.

Our linear regression model with fixed effects attempts to explain espresso prices using three variables: GDP per capita, consumers' price index and the potential number of inhabitants per bar. As for the GDP, it clearly affects positively the espresso price. In our formulation of Dastidar's model, GDP is proxied by parameter $a$, any increase in which obviously causes an increase in the equilibrium price. The effect of a change in the consumers' price index, which could perhaps be captured by a variation in the cost parameters $b$ and $c$ appearing in the cost function, is not statistically significant.

Finally, notice that a decrease in the potential number of inhabitants per bar is equivalent to an increase in the number of bars for any given size of consumers' population. The empirical finding is that an increase in the number of bars (firms) significantly increases espresso prices. The theoretical counterpart of this finding is that firms react to the procompetitive impact of an increase in their number by drifting away from both average and marginal cost pricing through $\alpha$. If firms overreact to a decrease in industry concentration by increasing $\alpha$ more than proportionally, then price increases.

Remembering that $\alpha$ may be interpreted as markup (on the average cost), our story is one in which the average market price in each city emerges from two countervailing forces: entry and markup adjustment. In this context, firms response to an increase in their number and of the competitive pressure may go through a compensating anti-competitive upward adjustmenst of the markup. 


\section{Conclusions}

This paper has provided some preliminary evidence on the price of espresso in Italian cities. Espresso in Italy is an extremely homogeneous good, usually consumed by people at the counter of bars, with a significantly stable price within each city. The bars are mostly independent establishments, not part of chains. Our empirical analysis, however, documents two important facts: first, espresso prices are rather dispersed in Italian regional capital cities; second, prices tend to be higher in cities with more bars per capita. We relate this evidence to the relevant literature and we argue that the most plausible theoretical explanation, consistent with the characteristics of the sector and of the evidence provided, is based upon variable markups and the Dastidar (1995) model of price competition with convex costs. Unlike other models yielding similar conclusions as for the relationship between price and the intensity of competition, the model does not require product differentiation, search costs, nor goods to be traded. Overall, the paper has provided preliminary but quite robust results about price dispersion in the Italian coffee sector and has rationalized the evidence within an appropriate although relatively less explored theoretical model.

The major limition of our study is the limited amount of data that are currently available on coffee and bars in Italy. Our data were obtained from several sources including a bar category association. Regrettably, it seems unlikley that more detailed information may become available in the nearest future.

Acknowledgments We would like to thank the editor and two anonymous referees that provided very helpful comments, Gianluigi Bovini and Franco Chiarini of Bologna City Council for the data that they provided. The usual disclaimer applies.

Open Access This article is distributed under the terms of the Creative Commons Attribution 4.0 International License (http://creativecommons.org/licenses/by/4.0/), which permits unrestricted use, distribution, and reproduction in any medium, provided you give appropriate credit to the original author(s) and the source, provide a link to the Creative Commons license, and indicate if changes were made.

\section{Appendix: A}

\section{A.1 Construction of the Dataset}

The lack of data on bars selling espresso constitutes a serious obstacle to our statistical analysis. We outline here the strategy adopted to construct a workable dataset. The units of analysis are the 20 regional capital cities of Italy. The following are the original data sources available. ISTAT has data about the price of espresso but these are available only for the years 2005 and 2009. Data from the Italian Census, also published by ISTAT, provide us with the number of eating and drinking establishments in each city for years 2001 and 2011. For year 2011 the exact number of bars is also available. Data on GDP per capita at current prices (Eurostat) ${ }^{17}$ and on the Consumers' Price Index and the Total Adult Population (ISTAT) are available for all the years in the study.

On the basis of these original sources, we do two exercises. First, we need to estimate the number of bars. For 2001 we use the proportion of bar over the total number of eating

\footnotetext{
${ }^{17}$ Eurostat provides data on GDP at province levels. In the Eurostat taxonomy, the Italian provinces correspond to NUTS3.
} 
and drinking establishments in 2011. For the remaining years, 2005 and 2009, we calculate the number of bars by interpolating the original data on establishments in 2001 and 2011 and then using again the 2011 proportion to estimate the number of bars in those years. The underlying assumption is that the proportion of bars over the total number of establishments has not changed throughout the 2001-2011 period. In other words, the data-generation process relies upon the conjecture that the number of bars were not subject to any technological, demand or supply shock in the ten years time span considered: given the characteristics of the sector (very homogeneous product, very low technology, very customary clients) our conjecture and the resulting constant rate appears justified.

Second, we need to estimate the price of espresso for years 2001 and 2011. A very similar reasoning was adopted. Given the original 2005 and 2009 data, we interpolate them linearly to calculate the estimated espresso prices for years 2001 and 2011.

\section{A.2 The Dataset: Robustness Checks}

In the light of the difficulties discussed above in constructing the dataset for the analysis, it is extremely important to check the robustness of them. To do so, in this section we test two alternative specifications. The first specification includes only the years for which we have original information on the number of eating and drinking establishments, i.e. 2001 and 2011. The second specification includes only the years for which original data on espresso prices are available, i.e. 2005 and 2009.

Table 3 reports the results for these two specifications in columns (1) and (2) respectively. Column (1) shows that our results are extremely robust to the first of our new, reduced specifications. The signs and significance are comparable and even the magnitude of the effects is almost unaffected. The results are less encouraging when focusing on Column (2). In that specification, covering years 2005 and 2009, the number of inhabitants per bar has a positive effect on espresso prices. The effect, however, has a very small magnitude and it is not statistically significant ( $\mathrm{p}$-value $\simeq 0.81$ ). GDP per capita is also not significant and all the effects seem to be captured by the consumers' price index, that is highly significant. A look at the descriptives for years 2005 and 2009, however, seems to confirm the evidence provided in the main text. Figure 3 shows a weaker but negative relationship between the price of espresso and the inhabitants per bar. On top of that the correlation coefficient between

Table 3 Espresso price: robustness checks

\begin{tabular}{lll}
\hline & $(1)$ & $(2)$ \\
& $2001-2011$ only & $2005-2009$ only \\
\hline Inhabitants & $-0.061702^{* * * *}$ & 0.005125 \\
& $(0.013277)$ & $(0.021477)$ \\
GDPpc & $0.022716^{* * *}$ & -0.034596 \\
& $(0.006977)$ & $(0.0050634)$ \\
Price Index & -0.000632 & $0.009313^{* * *}$ \\
& $(0.000342)$ & $(0.001617)$ \\
Constant & $0.599450^{* *}$ & -0.264686 \\
& $(0.213104)$ & $(0.276885)$ \\
$R^{2}$ & & \\
Obs & 0.4916 & 0.0058 \\
& 38 & 37
\end{tabular}




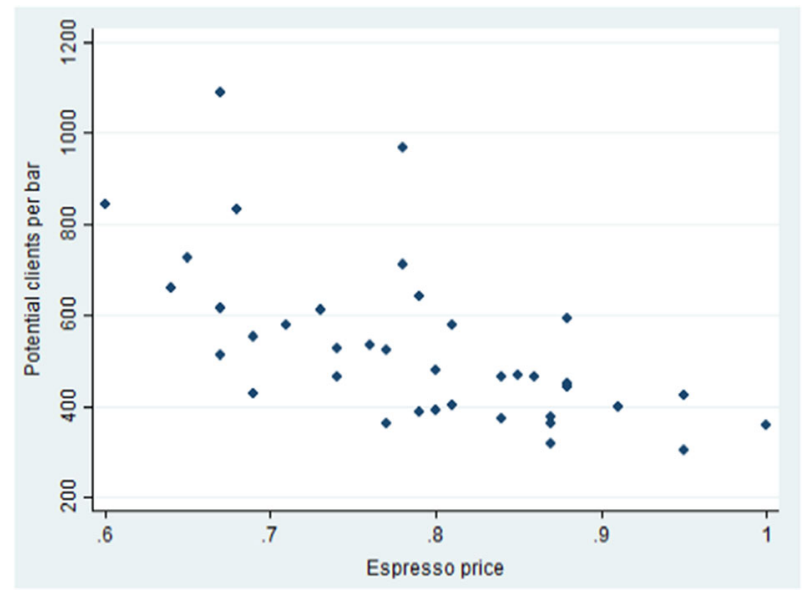

Fig. 3 Inhabitants per bar and espresso prices, 2005-2009

these two variables is still -0.6262 . The regression results in (2), instead, might be affected by the reduced number of observations when focusing only on two years.

\section{A.3 Statistical Sources}

Bologna City Council (2009), "I redditi 2005 dichiarati dalle cittadine e dai cittadini di Bologna: alcune disuguaglianze fra generazioni, generi, nazionalità e territori", ("The 2005 declared income of citizens of Bologna: some inequalities between generations, genders, nationalities and territories", in Italian). Available upon request.

Bologna City Council (2014), "I redditi 2012 dichiarati dalle cittadine e dai cittadini di Bologna: alcune disuguaglianze fra generazioni, generi, nazionalità e territori", ("The 2012 declared income of citizens of Bologna: some inequalities between generations, genders, nationalities and territories", in Italian). Available at: http://www.comune.bologna.it/ iperbole/piancont/Redditi/PRES_REDDITI_2012.pdf

EUROSTAT, GDP per capita by province. Available at: http://ec.europa.eu/eurostat/ cache/RSI/\#?vis=nuts3.economy

FIPE (2013), "I veri conti della tazzina di caffé al bar", ("The real accounting of a coffee cup at the bar"), Federazione Italiana Pubblici Esercizi. Available at: http://www.fipe.it/ media-e-pubblicazioni/pubblicazioni-ed-editoriali/le-pillole-di-fipe.html

ISTAT, "Price Index by City" and "Population by City". Available at: http://sitis.istat.it/ sitis/html/

ISTAT, "Bars and eating and drinking establishments". Available at: http:// dati-censimentoindustriaeservizi.istat.it/

\section{References}

Baye M, Morgan J, Scholten P (2006) Information, search, and price dispersion. In: Hendershott T (ed) Handbook on economics and information systems. Elsevier

Chen Y, Riordan MH (2008) Price-increasing competition. RAND J Econ 39:1042-58

Crucini MJ, Yilmazkuday H (2014) Understanding long-run price dispersion. J Monet Econ 66:226-240 
Dastidar KG (1995) On the existence of pure strategy Bertrand equilibrium. Econ Theory 5:9-32

Dastidar KG (2001) Collusive outcomes in price competition. J Econ 73:81-93

Delbono F, Lambertini L (2016) Bertrand versus Cournot with convex variable costs. Econ Theory Bull 4:73-83

Eizenberg A, Lach S, Yiftach M (2016) Retail prices in a city. CEPR Discussion Paper 11590

Frankel, Gould (2001) The retail price of inequality. J Urban Econ 49:219-239

Goolsbee A, Syverson C (2008) How do incumbents respond to the threat of entry? Evidence from major airlines. Q J Econ 123:1611-33

Gori G, Lambertini L, Tampieri A (2014) Trade costs, FDI incentives, and the intensity of price competition. Int J Econ Theory 10:371-385

Gorodnichenko Y, Talavera O (2017) Price setting in online markets: basic facts, international comparisons, and cross-border integration. Am Econ Rev 107:249-282

Gorodnichenko Y, Sheremirov V, Talavera O (2015) Price setting in online markets: does IT click? Federal Reserve Bank of Boston Working Paper, 15-1

Marshall RC, Marx LM (2012) The economics of collusion: cartels and bidding rings. MITPress

Pauly MV, Sattherthwaite MA (1981) The pricing of primary care physicians' services: a test of the role of consumer information. Bell J Econ 12:488-506

Vives X (1999) Oligopoly pricing: old ideas and new tools. MITPress

Yilmazkuday H (2014) Price dispersion across US districts of entry. Econ Lett 123:361-365

Yilmazkuday H (2016) Constant versus variable markups: implications for the law of one price. Int Rev Econ Financ 44:154-168 